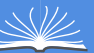

Global Journals Inc.

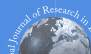

GLOBAL JOURNAL OF RESEARCHES IN ENGINEERING: J

GENERAL ENGINEERING

Volume 19 Issue 1 Version 1.0 Year 2019

Type: Double Blind Peer Reviewed International Research Journal

Publisher: Global Journals

Online ISSN: 2249-4596 \& Print ISSN: 0975-5861

\title{
Impact of Fabric Density, Color and Composition of Plain Weave Fabric on Ultraviolet Protective Factor
}

\author{
By Marzia Islam, Tarifun Akter, Jannatul Ferdush \& Kamrunnahar
}

Northern University

Abstract- In this study, the effect of fabric density and different colors (black and red) on ultraviolet protection factor of woven fabric investigated. The fabric of different composition (100\% cotton, 60/40 CVC), two color (black, red) and various density (Ends per inch, Picks per inch) collected. Then UPF rating was measured by spectrophotometer in vitro method. Experimental result showed that higher the fabric density and weight; higher the protection from ultraviolet rays. Besides, it also revealed that black fabric has more UV protection ability than the red one. Another finding of this study is that polyester content increases the UPF value.

Keywords: fabric density, composition, color, fabric weight, ultraviolet protective factor.

GJRE-J Classification: FOR Code: 291899

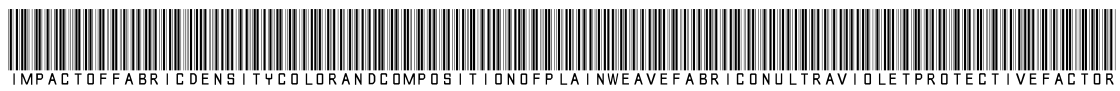

Strictly as per the compliance and regulations of:

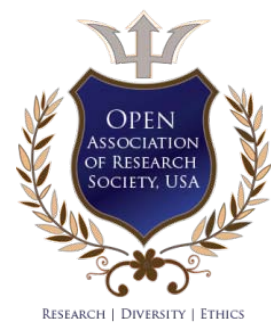

(C) 2019. Marzia Islam, Tarifun Akter, Jannatul Ferdush \& Kamrunnahar. This is a research/review paper, distributed under the terms of the Creative Commons Attribution-Noncommercial 3.0 Unported License http://creativecommons.org/licenses/by$\mathrm{nc} / 3.0 /$ ), permitting all non commercial use, distribution, and reproduction in any medium, provided the original work is properly cited. 


\title{
Impact of Fabric Density, Color and Composition of Plain Weave Fabric on Ultraviolet Protective Factor
}

\author{
Marzia Islam ${ }^{\alpha}$, Tarifun Akter $^{\sigma}$, Jannatul Ferdush ${ }^{\rho} \&$ Kamrunnahar $^{\omega}$
}

\begin{abstract}
In this study, the effect of fabric density and different colors (black and red) on ultraviolet protection factor of woven fabric investigated. The fabric of different composition (100\% cotton, 60/40 CVC), two color (black, red) and various density (Ends per inch, Picks per inch) collected. Then UPF rating was measured by spectrophotometer in vitro method. Experimental result showed that higher the fabric density and weight; higher the protection from ultraviolet rays. Besides, it also revealed that black fabric has more UV protection ability than the red one. Another finding of this study is that polyester content increases the UPF value.
\end{abstract}

Keywords: fabric density, composition, color, fabric weight, ultraviolet protective factor.

\section{InTRODUCTION}

S kin disease including skin cancer has become very common now a days. UV radiation from sun is the primary cause for skin cancer according to many researchers $[1,2]$. Sun radiation has a continuous energy spectrum radiates from sun in the wavelength range of about $0.7 \mathrm{~nm}$ to $3000 \mathrm{~nm}$. Only $280 \mathrm{~nm}$ to 3000 $\mathrm{nm}$ solar radiation can reach on the earth surface [3], where the wavelength of the ultraviolet spectrum lies between $290 \mathrm{~nm}$ to $400 \mathrm{~nm}$. Overexposure to UVR has the most adverse impact onerythema and skin cancer, which increased the public awareness of adopting personal UV protective schemes such as the use of sunscreen on the exposed parts of body [4]. Besides using sunscreen and shading, people can also cover their body by wearing textile garments to protect from UVR $[5,6,7]$. But before selection of garments the fabric parameters like fabric density, color, weight should be considered to get better UV protection. I. M. Algaba, Achwal, B. R Daset al. showed the effect of thickness and weight on UV protection of cellulosic woven fabric $[8,9,10]$. Moon and Pailthorpe found that stretching elastane-based garments have lower UPF than unstretched garment [11]. To make a comparison of the ultraviolet protection factor of different composition, weight and color plain fabric is the aim of this study.

\section{il. Material and Method}

Two color black and red $100 \%$ cotton and $60 \%$ cotton $40 \%$ polyester plain fabric of different ends per inch, picks per inch collected from Evince limited. Then the samples are conditioned at relative humidity $65 \pm 2 \%$, Temperature $20 \pm 2^{0} \mathrm{C}$ at least 24 hours.

UPF Measurement: In this study, ultraviolet protective factor (UPF) represented the UV protective capabilities of woven fabrics from sunburn as a quantitative indicator. UV protection ability of cotton and blended plain fabrics measured by vitro approach. Ultraviolet protection factor in the vitro measurement conducted with a spectrophotometer in accordance with the AS/NZS 4399 standard.

Following is the equation of calculating UPF:

$$
\mathrm{UPF}=\frac{\sum_{290}^{400} E_{\lambda} S_{\lambda} \Delta_{\lambda}}{\sum_{290}^{400} E_{\lambda} S_{\lambda} T_{\lambda} \Delta_{\lambda}}
$$

Where,

$E_{\lambda}$ is the erythemal spectral effectiveness.

$S_{\lambda}$ is the solar spectral irradiance (in $\mathrm{W} \cdot \mathrm{m}-2 \cdot \mathrm{Nm}-1$ ).

$T_{\lambda}$ is the spectral transmission through the textile.

$\Delta_{\lambda}$ is the bandwidth (in $\mathrm{nm}$ ).

And $\lambda$ is the wavelength (in $\mathrm{nm}$ ) [12].

The current Australian/New Zealand Standard has three major categories According to Australian Radiation Protection and Nuclear Safety Agency (ARPANSA),

\begin{tabular}{|c|c|c|}
\hline UPF Rating Protection & Category & \% UV Radiation Blocked \\
\hline $15-24$ & Good & $93.3-95.9$ \\
\hline $25-39$ & Very Good & $96.0-97.4$ \\
\hline 40 and over & Excellent & 97.5 or more \\
\hline
\end{tabular}

Author a $\sigma \rho \omega:$ Lecturers of Northern University, Bangladesh. e-mail: barna091@yahoo.com 
Measurement of fabric density and weight: Fabric density means the ends per inch along the length and picks per inch along width measured according to ASTM D3775 - 17e1. Fabric GSM measured according to ASTM D3776M - 09a (2017).

\section{iil. Result and Discussion}

The value of UPF increases with the increasing fabric density and weight for similar composition. To inspect the relationship between UPF, weight, composition, color and density, two approaches used here. One is investigating the change of UPF having same construction on different composition and another one is an identical composition having a different construction.

Table 2: Relationship of UPF with fabric density, composition, color and weight

\begin{tabular}{|c|c|c|c|c|}
\hline Composition & GSM & EPI*PPI & Color & UPF \\
\hline \multirow{2}{*}{$100 \%$ cotton } & \multirow{2}{*}{130} & \multirow{2}{*}{$132 * 72$} & Black & 28 \\
\hline & & & Red & 13 \\
\hline \multirow{2}{*}{$60 \%$ cotton $40 \%$ polyester } & \multirow{2}{*}{130} & \multirow{2}{*}{$132 * 72$} & Black & 35 \\
\hline & & & Red & 17 \\
\hline \multirow{2}{*}{$100 \%$ cotton } & \multirow{2}{*}{160} & \multirow{2}{*}{$144 * 80$} & Black & 32 \\
\hline & & & Red & 15 \\
\hline \multirow{2}{*}{$60 \%$ cotton $40 \%$ polyester } & \multirow{2}{*}{160} & \multirow{2}{*}{$144 * 80$} & Black & 41 \\
\hline & & & Red & 22 \\
\hline
\end{tabular}

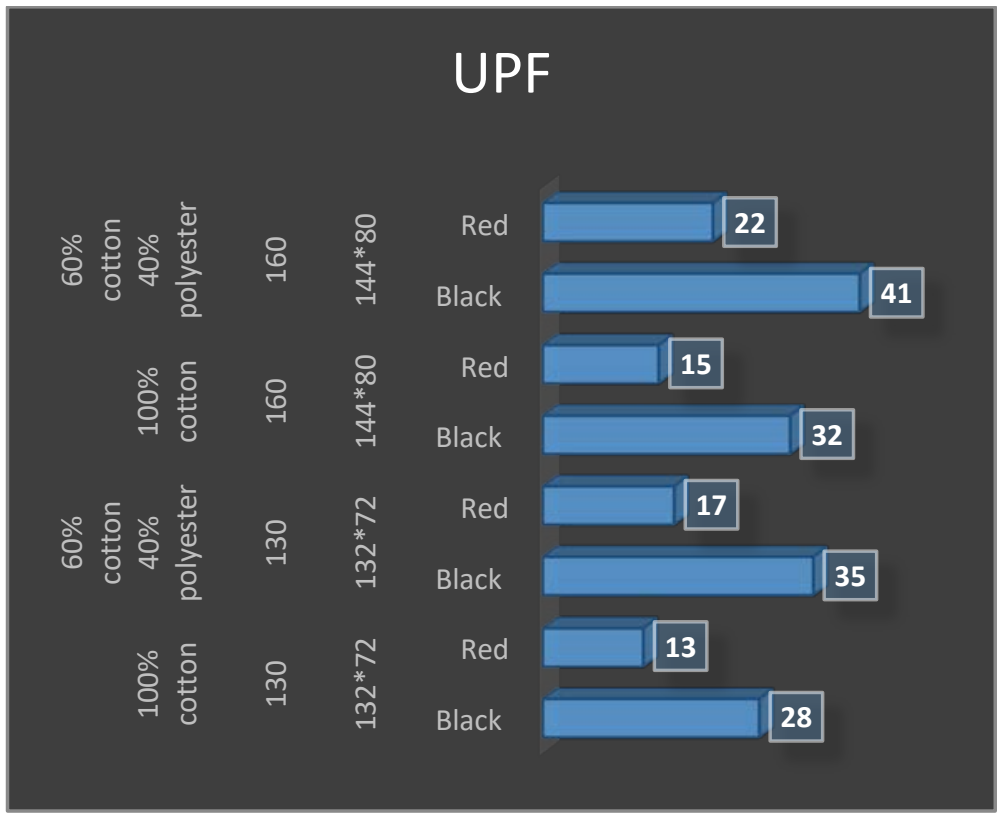

Figure 1: Relationship between color, weight and UPF rating.

As shown in figure $01,100 \%$ cotton fabric has less UV protection power than the blended one. So polyester content in blended fabric enhances the UPF. Moreover, black color fabric has more UPF than red. Another finding of this study is the same color and identical composition fabric has different UPF because of different fabric density and weight. Higher the EPI and PPI values, higher the UPF value.

\section{Conclusion}

This whole work is intended to establish a general idea on the issue of UV protection factor of a plain weave fabric simply. Considering fabric density, color and composition as main variables, UPF ratings are measured for different types of sample. UPF enhances with the increasing density, weight, the blended composition shows better value than the pure one, and black color shows excellent protection against UV. Though there are many other factors which can directly or indirectly influence the UV protection factor, here only a few represented. Also, establish a comparison among them. In addition, the most mentionable comparison is polyester has more UPF value than cotton. 


\section{REFERENCES RÉFÉRENCES REFERENCIAS}

1. R. N. Saladi and A. N. Persaud, "The causes of skin cancer: a comprehensive review," Drugs of Today, vol.41, no.1, pp. 37-53, 2005.

2. D. L. Narayanan, R. N. Saladi, and J. L. Fox, "Ultraviolet radiation and skin cancer," International Journal of Dermatology, vol. 49, no.9, pp. 978-986, 2010.

3. G. Reinert, F. Fuso, R. Hilfiker, and E. Schmidt "UVProperties of textile fabrics and their improvement", Text. Chem. Color., vol. 29, no. 12, pp. 36-43, 1997.

4. W. Y. Wong, J.K.C. Lam, C. W. Kan, and R. Postle, "Influence of knitted fabric construction on the ultraviolet protection factor of greige and bleached cotton fabrics," Textile Research Journal, vol.83, no.7, pp. 683-699, 2013.

5. D. G. Stanford, K. E. Georgouras, and M.T. Pailthorpe, "Rating clothing for sun protection: current status in Australia," Journal of the European Academy of Dermatology \& Venereology, vol.8, no.1, pp. 12-17, 1997.

6. P. H. Gies, C. R. Roy, S. Toomey, and A. McLennan, "Protection against solar ultraviolet radiation," Mutation Research - Fundamental and Molecular Mechanisms of Mutagenesis, vol. 422, no. 1, pp. 15-22, 1998.

7. H. P. Gies, C. R. Roy, G. Holmes, A. F. Mc Kinlay, and M. H. Repacholi, "Ultraviolet radiation protection by clothing: comparison of in vivo and in vitro measurements," Radiation Protection Dosimetry, vol. 91, no. 1-3, pp. 247-250, 2000.

8. W. B. Achwal, "Sun protection properties of textile substrates," Color age, vol. 44, no. 5, pp. 31-32, 1997.

9. B. R. Das, "UV radiation protective clothing," The Open Textile Journal, vol. 3, pp. 14-21, 2010.

10. I. M. Algaba, M. Pepi'o, and A. Riva, "Correlation between the ultraviolet protection factor and the weight and thickness of undyed cellulosic woven fabrics," Fibres and Textiles in Eastern Europe, vol.16, no. 1, pp. 85-89, 2008.

11. Moon R, Pailthorpe M. "Effect of stretch and wetting on the UPF of elastane fabrics." Australas Textiles, vol. 15, pp. 39-42, 1995.

12. C. W Kan, "A Study on ultraviolet protection of $100 \%$ Cotton Knitted Fabric: Effect of Fabric Parameters", The Scientific World Journal, 2014.

13. The Australian Radiation Protection and Nuclear Safety Agency, April 2008. 